\title{
Ultrasonographic monitoring of antral follicle development in red deer (Cervus elaphus)
}

\author{
G. W. Asher ${ }^{1}$, I. C. Scott ${ }^{1}$, K. T. O’Neill ${ }^{1}$, J. F. Smith ${ }^{2}$, E. K. Inskeep ${ }^{3}$ \\ and E. C. Townsend ${ }^{3}$ \\ ${ }^{1}$ AgResearch, Invermay Agricultural Centre, Private Bag 50034, Mosgiel, New Zealand; ${ }^{2}$ AgResearch, \\ Ruakura Agricultural Centre, Private Bag 3123, Hamilton, New Zealand; and ${ }^{3}$ Division of Animal and \\ Veterinary Sciences, West Virginia University, Morgantown, WV 26506-6108, USA
}

\begin{abstract}
Ovarian follicular dynamics were monitored in 12 surgically modified red deer hinds (ovaries adhered to vaginal wall) by transvaginal real-time ultrasonography during the luteal cycle, anoestrus and induction of superovulation. All 12 hinds showed evidence of regular luteal (plasma progesterone) cyclicity during the breeding season, although luteal tissue was not observed on the ultrasonograms. During the normal luteal cycle (14-22 days) total numbers of follicles $>3 \mathrm{~mm}$ did not vary significantly by day (range of means: 1.8-3.4; $P>0.05)$. A single large $(\geq 6 \mathrm{~mm})$ follicle was usually present on all days except immediately after ovulation (day 0 ). However, the appearance of new follicles ( $\geq 3 \mathrm{~mm}$ ) was not random, and was greatest on day 1 and day $14(P<0.05)$. Tracking of individual follicles revealed irregular waves of emergence and disappearance of the largest follicle, with either one $(n=1)$, two $(n=3)$ or three $(n=5)$ waves observed across nine luteal cycles. New follicles $(\geq 3 \mathrm{~mm})$ emerged after regression or ovulation of a large follicle, suggesting a dominance effect. There were no significant differences in the overall mean numbers of follicles during early, mid- and late anoestrus (September, November and April, respectively) but follicle turnover was more rapid during mid-anoestrus as evidenced by a significantly greater number of new small $(>3 \mathrm{~mm})$ follicles $(P<0.001)$. Administration of superovulatory doses of ovine FSH during the breeding season resulted in a marked increase in the appearance of new follicles within $48 \mathrm{~h}$ of initiation of the injection regimen. By termination at $96 \mathrm{~h}$, the time of progesterone withdrawal, the mean number of follicles $>3 \mathrm{~mm}$ was significantly higher than for control hinds (9.8 versus $3.0 ; P<0.001)$. While most follicles ovulated progressively 2-7 days later, about $40 \%$ persisted beyond this period. The study demonstrated the presence of discrete patterns of antral follicle growth and regression during the breeding and non-breeding seasons, with the luteal cycle characterized by a variable number (I-3) of dominant follicle waves. Anoestrus represents a period of dynamic changes in follicular turnover.
\end{abstract}

\section{Introduction}

Red deer (Cervus elaphus scoticus) are highly seasonal breeders, with mating activity in autumn and calving in summer (Lincoln and Short, 1980). With adequate nutrition and when other environmental and social factors are not limiting, this species exhibits high fertility, with $>95 \%$ of mature females bearing singleton calves each year (Clutton-Brock et al, 1982). For farmed red deer in New Zealand it has been shown that such high pregnancy rates reflect high conception at a given ovulation, being approximately $85 \%$ after natural mating (Fennessy et al., 1991; Asher et al., 1993). However, in the enforced absence of pregnancy, red deer hinds are polyoestrous, and are capable of exhibiting between four and

Received 13 February 1997. nine continuous 17-19 day oestrous cycles over a 3-6 month period between autumn and spring (Guinness et al., 1971; Duckworth and Barrell, 1992; Meikle and Fisher, 1996). Although luteal events during the oestrous cycle have been well described for this species based on characterization of the timing of ovulation relative to oestrus (Asher et al., 1992) and luteal progesterone secretion (Adam et al., 1985; Jopson et al., 1990), little is known of ovarian follicular dynamics during the oestrous cycle and the respective breeding and non-breeding seasons.

Application of real-time ultrasonography in monitoring ovarian function in mammals has advanced our understanding of follicular dynamics. In domestic ruminants such as cattle, sheep and goats, ultrasonography has revealed non-random emergence of follicles, particularly during the oestrous cycle. For cattle in particular, numerous studies over the last decade 
have shown 2-3 successive 'waves' of antral follicle emergence during the 20-23 day oestrous cycle, with a single follicle from each wave 'selected' to undergo further development at the expense of all other subordinant follicles. Thus, two or three successive 'dominant' follicles will occur during the cycle depending on the duration of the ovarian cycle, with the last selected follicle attaining ovulatory status (Sirois and Fortune, 1988; Ginther et al., 1989). Whereas cattle are almost invariably monovular and exhibit marked primary follicle dominance (Fortune, 1993), sheep and goats are generally polyovular and multiple large follicles appear to exert less dominance over subordinant follicles (Schrick et al., 1993; Ginther and Kot, 1994; Ravindra et al., 1994; Johnson et al., 1996).

The roles of follicular dominance and waves, respectively, appear to be to regulate ovulation rate and to ensure the presence of an ovulatory follicle(s) and viable ovum (ova) immediately after luteolysis. The pre-emptive ovulatory follicle(s) has generally emerged as a primary follicle from the recruitment pool within the last 6 days of the oestrous cycle, having been preceded by one or more large follicles doomed to undergo atresia. Artificial prolongation of the longevity of the ovulatory follicle is associated with oocyte senescence, reduced fertilization of ova or abnormal embryonic development (Wishart, 1977; Mihm et al., 1994).

Reproduction in red deer is characterized by a high frequency of single ovulations, high conception rates and strong expression of seasonality. Therefore, it seems reasonable to hypothesize that this species would exhibit very precise, non-random patterns of follicular growth and dominance, and marked seasonal changes in follicular dynamics. In the present study, these hypotheses were tested using ultrasound to record ovarian antral follicular dynamics in red deer hinds. Luteal function was monitored by profiling progesterone secretion.

\section{Materials and Methods}

\section{Animals and management}

Twelve mature (5-10 years old) red deer hinds at the Invermay Agricultural Centre $\left(45^{\circ} 53^{\prime} \mathrm{S}, 170^{\circ} 21^{\prime} \mathrm{E}\right.$ ) were used in this study from March to December 1994. All had been surgically modified in February 1994 so that their ovaries were attached to the vaginal wall. They were grazed outdoors in close proximity to other red deer of both sexes, and were offered supplements of meadow hay in winter. This study was undertaken with the approval of the AgResearch Invermay Animal Ethics Committee, as required by the Animal Welfare (Codes of Ethical Conduct) Act 1987.

\section{Surgical procedures}

A total of 14 hinds was fasted for at least $18 \mathrm{~h}$ before anaesthesia was induced with an i.m. injection of an aqueous mixture containing $58.3 \mathrm{mg}$ xylazine hydrochloride $\mathrm{ml}^{-1}$, $3.2 \mathrm{mg}$ azaperone $\mathrm{ml}^{-1}$ and $0.4 \mathrm{mg}^{-1}$ fentanyl citrate $\mathrm{ml}^{-1}(2 \mathrm{ml}$ Fentazin; Parnell Laboratories, Auckland). They were then intubated and anaesthesia was maintained with halothaneoxygen. Uterine relaxation was induced with an i.v. injection of $0.5 \mathrm{mg}$ clenbuterol hydrochloride $(5 \mathrm{ml}$ Planipart; Boehringer
Ingelheim (NZ) Ltd, Auckland) approximately $5 \mathrm{~min}$ before laparotomy. The reproductive tract was accessed via a midline incision, exteriorized, and the ovarian ligaments detached from the uterus by cautery, leaving the ovarian artery and vein intact. Each ovary was then translocated alongside the midvaginal wall and sutured in place after slight scarification of the adjacent vaginal wall to induce adhesion. After closure of the incision, each hind received an i.m. injection of long-acting antibiotic (10 $\mathrm{ml}$ Propen LA; Glaxo NZ Ltd, Auckland) and the anaesthesia was reversed by an i.v. injection of $50 \mathrm{mg}$ yohimbine hydrochloride $(5 \mathrm{ml}$ Recervyl; Aspiring Animal Services, Wanaka). The deer were left to recover for 26 days before commencement of ultrasonography. Two hinds were subsequently eliminated from the study because of problems with locating and visualizing their ovaries by ultrasonography.

\section{Ovarian monitoring}

Ultrasonographic scanning was performed by a single operator using a $7.5 \mathrm{MHz}$ linear array transducer (Aloka SSD 210; MedTel Telectronics Ltd, Auckland). The probe was held rigid in a specially modified aluminium shaft to enable exterior manipulation of the transducer. During ultrasonography, the hinds were restrained in an upright position in a pneumatically controlled crush designed specifically for red deer. A liberal coating of carboxymethylcellulose was applied to the transducer, which was then inserted carefully into the vagina until an echo-image of the bladder was observed. The probe was then gently rotated $90^{\circ}$ clockwise and $180^{\circ}$ counter clockwise while it was moved forward, until the ovaries were located. The antral diameters of all follicles $\geq 3 \mathrm{~mm}$ were measured using the in-built scanner callipers, and their three-dimensional position and size were recorded. Follicles were recorded to the nearest millimetre.

\section{Seasonal patterns of follicular turnover}

Ovarian scanning was performed on the 12 hinds each day for 30 days from 28 March (early breeding season), for 25 days from 7 June (mid-breeding season), for 30 days from 12 September (late breeding season) and for 26 days from 14 November (anoestrus). Ovarian cycles had not been previously synchronized, although an additional study conducted in July-August (see below) involved artificial synchronization that may have promoted a degree of synchrony in September.

\section{Follicular response to exogenous $F S H$}

The hinds were scanned each day for 15 days at the initiation of treatment aimed at inducing a superovulatory response (Fennessy et al., 1994). All hinds received an intravaginal progesterone-releasing device (Eazi-Breed CIDR device, $0.3 \mathrm{~g}$ progesterone; Inter $\mathrm{Ag}$, Hamilton) for 12 days from 24 July, with device replacement on day 8. Six hinds within the group received eight equal-dose i.m. injections of ovine FSH (total of 0.4 iu Ovagen; Immuno-Chemical Products Ltd, Auckland; equivalent to $72 \mathrm{iu}$ of NIH-FSH-S $)$ at $12 \mathrm{~h}$ intervals initiated at CIDR device replacement (1 August). The 
final injection also incorporated 200 iu eCG (Folligon; Intervet, Lane Cover, NSW). The remaining six hinds were treated with CIDR devices only. Scanning was initiated at the time of CIDR device replacement (first FSH injection) and necessitated temporary removal of devices for the duration of monitoring (3-5 min) during the first 4 days. All hinds received an i.m. injection of $500 \mu \mathrm{g}$ cloprostenol (2 ml Estrumate; Coopers Animal Health NZ, Upper Hutt) on day 15 of scanning to remove luteal tissue (Fisher et al., 1994).

\section{Blood sampling and hormonal analysis}

Blood samples were collected into heparinized tubes by jugular venepuncture daily during scanning and three times per week at other times during the year. Plasma was removed after centrifugation at $1000 \mathrm{~g}$ for $15 \mathrm{~min}$ within $2 \mathrm{~h}$ of collection and stored at $-20^{\circ} \mathrm{C}$ until assayed.

Plasma progesterone concentrations were measured by direct radioimmunoassay to determine the incidence and duration of luteal cyclicity. The assay has been validated previously for red deer plasma (Asher, 1990; Asher et al, 1992). All samples from an individual were included in a single assay. Control samples with low, medium and high concentrations of progesterone were included at frequent intervals within each assay. The interassay coefficients of variation were $15.2 \%$ for the low control (mean $0.4 \mathrm{ng} \mathrm{ml}^{-1}$ ), $8.9 \%$ for the medium control $\left(4.7 \mathrm{ng} \mathrm{ml}^{-1}\right)$ and $8.2 \%$ for the high control $(9.7 \mathrm{ng}$ $\mathrm{ml}^{-1}$ ) samples, respectively. The intra-assay coefficients of variation were $12.8 \%, 6.9 \%$ and $6.9 \%$ for the three control samples, respectively. Sensitivity of the standard curve, defined as the first point that was significantly different from 0 , was $0.1 \mathrm{ng} \mathrm{ml} \mathrm{m}^{-1}$.

\section{Data handling and statistical analysis}

Luteal cyclicity was assessed from longitudinal profiles of plasma progesterone concentrations in the absence of data on the incidence of behavioural oestrus. An interovulatory interval (hereafter termed a 'luteal cycle') was defined as the period between two troughs in progesterone secretion during which plasma concentrations remained below $0.3 \mathrm{ng}$ progesterone $\mathrm{ml}^{-1}$ for at least 2 days (a periovulatory period), and there was a progressive increase and decrease in progesterone secretion in the intervening period such that peak plasma concentrations exceeded $1.5 \mathrm{ng}$ progesterone $\mathrm{ml}^{-1}$ (a luteal phase; after Jopson et al., 1990). The day of ovulation (day 0) was defined as the day of lowest progesterone concentration before a sustained increase, coinciding with the disappearance of a large follicle that had previously been identified and tracked for several days. As oestrous behaviour was not observed, the term 'oestrous cycle' is not used.

Two approaches were used to describe and examine the follicular dynamics of both cyclic and non-cyclic hinds. First, numbers of small $(3 \mathrm{~mm})$, medium $(4-5 \mathrm{~mm})$, large $(\geq 6 \mathrm{~mm})$, new and total follicles present, and mean size of all follicles present on any day were recorded and compared among days of the luteal cycle, between short and normal cycles, or between months. Second, identification of individual follicles was performed retrospectively from ovarian maps plotted from

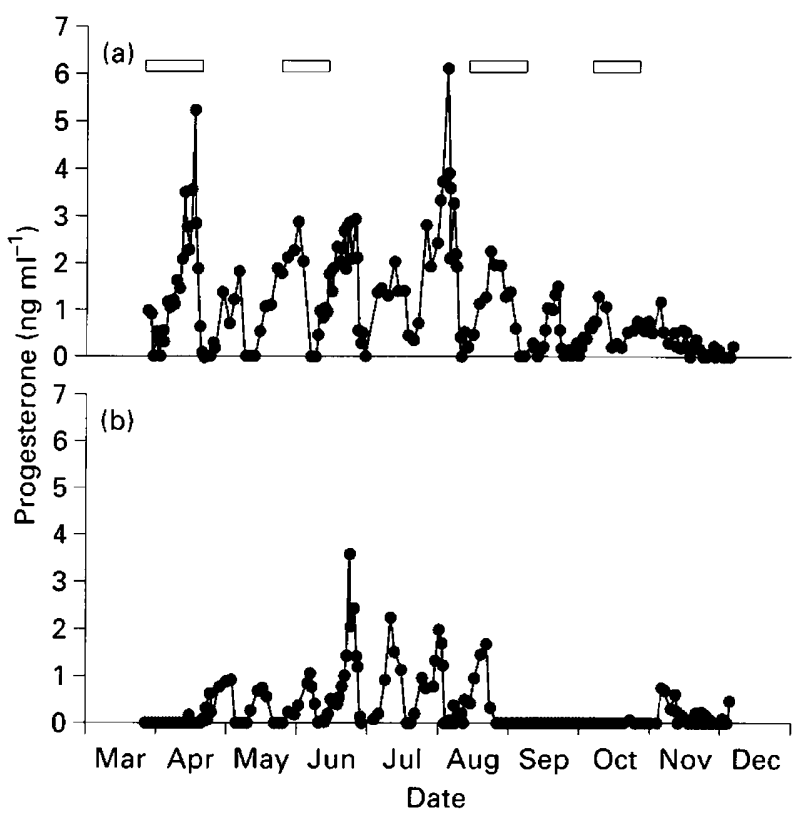

Fig. 1. Representative profiles of concentrations of plasma progesterone of two red deer hinds during the course of the study. The profiles contrast individuals with (a) a relatively long period of luteal cyclicity (about 200 days) and (b) a relatively short breeding season (about 130 days). Horizontal bars indicate periods of daily ultrasonographic monitoring of ovaries.

the daily measurements. The diameters of identified follicles were tabulated so that the growth and regression (or ovulation) of each follicle could be tracked over the monitoring period. The initial, maximum, last and average diameters of follicles that could be tracked from emergence to disappearance at least 2 days later, and the number of days the follicle was present, were then compared among seasons (months), between cycles of short or normal duration, or between ovulatory (OvF) and non-ovulatory $(\mathrm{NOvF})$ follicles within a luteal cycle. If a follicle could not be identified from a previous day, it was deemed to be a new follicle. Abrupt disappearance of tracked follicles $\geq 6 \mathrm{~mm}$ was deemed to represent ovulatory rupture on the day of disappearance.

For these statistical analyses, data on follicles from both ovaries of each animal were combined. All comparisons were made by analysis of variance (Steel and Torrie, 1980), using the GLM procedure of SAS 6.08 (1992).

\section{Results}

\section{Luteal and follicular cyclicity}

All 12 hinds exhibited cyclic patterns of progesterone secretion indicative of luteal cyclicity (Adam et al., 1985; Jopson et al., 1990) between April and October (Fig. 1). Between seven and nine distinct luteal cycles of 14-22 days were observed for individual hinds, although the distinction between luteal events and random fluctuations in progesterone secretion became unclear for some hinds towards the end of the 

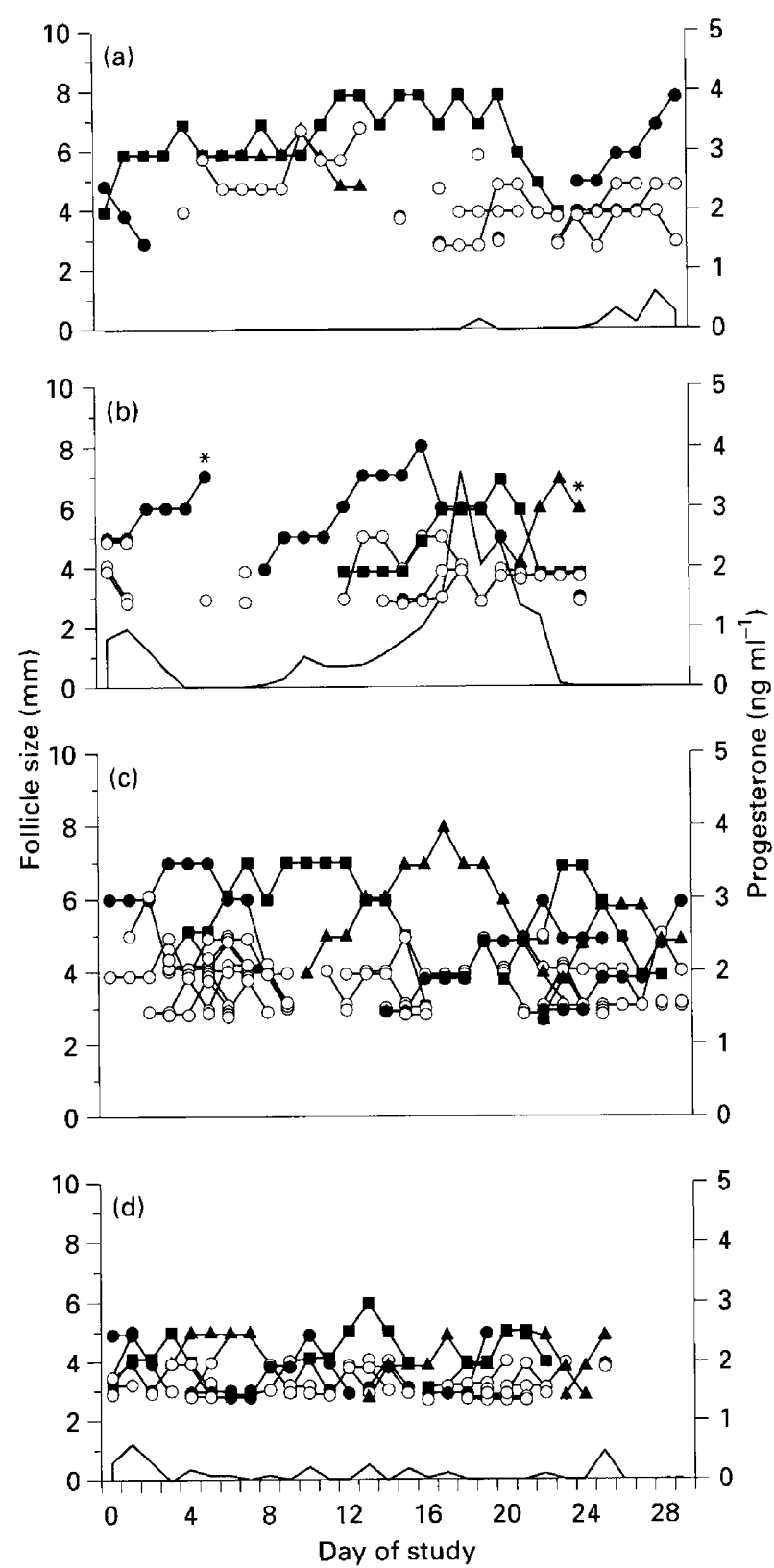

Fig. 2. Profiles for a single hind of 'dominant' follicles (that is, follicles that attained the largest diameter at any stage; - $\mathbf{0}, \mathbf{4}$ ) and subordinate follicles (O) plotted relative to plasma progesterone concentrations (shaded area) during ultrasonographic monitoring in (a) April, (b) June, (c) September, and (d) November. *Indicates follicular rupture (ovulation).

breeding season in October-November (Fig. 1a). In general, however, anoestrus was characterized by plasma progesterone concentrations below $0.3 \mathrm{ng} \mathrm{ml}^{-1}$ but with occasional transient (8-10 days) increases to $0.5-1.0 \mathrm{ng} \mathrm{ml}^{-1}$ observed in late anoestrus (Fig. Ib).

The ovaries of all 12 hinds remained functional during the entire study period, as evidenced by continuous turnover of follicles at all scan times (Fig. 2). However, there were some anomalies observed, principally the formation of exceptionally large follicles in four of the hinds.

\section{Follicular dynamics during the normal luteal cycle}

Nine complete luteal cycles of between 14 and 22 days (18 \pm 4 days) were analysed with respect to the total recorded follicle population $(\geq 3 \mathrm{~mm}$ ) on each day and individual follicles tracked during the cycle.

The mean number of follicles $\geq 3 \mathrm{~mm}$ present per day did not vary significantly $(P>0.1)$, ranging from 1.8 to 3.4 during the cycle (Fig. 3). However, mean daily follicular size did vary significantly $(P<0.05)$, with the largest mean sizes (approximately $7.0 \mathrm{~mm}$ ) occurring on days $8-10$ and days $15-18$ inclusive. The smallest mean size of $3.7 \mathrm{~mm}$ occurred on day 1 . There were significant differences in the number of new follicles $(\geqslant 3 \mathrm{~mm}$ appearing on any day $(P<0.05)$, ranging from a mean of 1.2 on day 14 to 0.1 on day 17 . When analysed in relation to size cohorts (Fig. 3a), it was found that the number of the smallest follicles $(3 \mathrm{~mm})$ was greatest on day $I$ and day 14 (means $=1.8$ and 1.1, respectively) and least on days 6, 8, 15 and 20 (mean $=0.1 ; \quad P<0.05$ ). Numbers of medium $(4-6 \mathrm{~mm})$ follicles present each day did not vary significantly during the ovarian cycle (means $=1.0-1.6 ; P>0.1$ ). The number of large $(>6 \mathrm{~mm}$ ) follicles was greatest on days 7-18 inclusive (range in means $=0.1$ (on day 2) -1.2 (on day 8 and day 17); $P<0.5$ ).

Individually tracked follicles were assigned as either ovulatory $(\mathrm{OvF})$ or non-ovulatory $(\mathrm{NOvF})$. The average day of appearance (that is, follicle $\geq 3 \mathrm{~mm}$ first observed) was day 11 for $\mathrm{OvF}$ and day 8 for NOvF $(P<0.05)$ but mean initial size (4.2 versus $3.6 \mathrm{~mm}$, respectively) was not significantly different $(P>0.1)$. Mean maximum size attained by follicles was $6.9 \mathrm{~mm}$ for $\mathrm{OvF}$ and $4.6 \mathrm{~mm}$ for $\mathrm{NOvF}(P<0.01)$, with maximum size reached at a mean time of day 15 for $\mathrm{OvF}$ and day 9 for $\mathrm{NOvF}$ $(P<0.01)$. The average last day of follicle presence was day 18 for OvF and day 10 for NOvF $(P<0.05)$, with a mean size of $6.2 \mathrm{~mm}$ and $3.8 \mathrm{~mm}$, respectively $(P<0.05)$. Persistence of follicles (that is, duration of observation) was 7.9 days for $\mathrm{OvF}$ and 3.7 days for $\mathrm{NOvF}(P<0.01)$.

During the normal luteal cycle there was variation in the longevity and in the number of the largest follicles occurring at any time (that is, the number of follicles that attained the largest size, but were not necessarily the ovulatory follicle). Of the nine cycles analysed, one cycle exhibited only a single large follicle $(\geq 6 \mathrm{~mm}$ ) that appeared on day 4 and ovulated on day 18 (Fig. 4a). Three cycles each had two consecutive large follicles (Fig. 4b), and five cycles each had three consecutive large follicles (Fig. 4c). However, emergence and regression sequences of these waves of large follicles were not synchronous by day of cycle within each cohort group. There was no evidence of a regular initiation of waves of follicular development.

\section{Follicular dynamics during short luteal cycles}

Four short luteal cycles of between 7 days and 9 days duration, all occurring at the onset of the breeding season in April ( $n=3$ hinds), were analysed in the same manner as for normal luteal cycles (Fig. 3b). In contrast to the normal luteal cycle, the mean daily number of follicles for short luteal cycles varied significantly $(P<0.001)$, with the greatest numbers recorded on days $4-5$ (Fig. 3b). Mean follicular diameter also varied significantly with time $(P<0.05)$, with the largest mean 


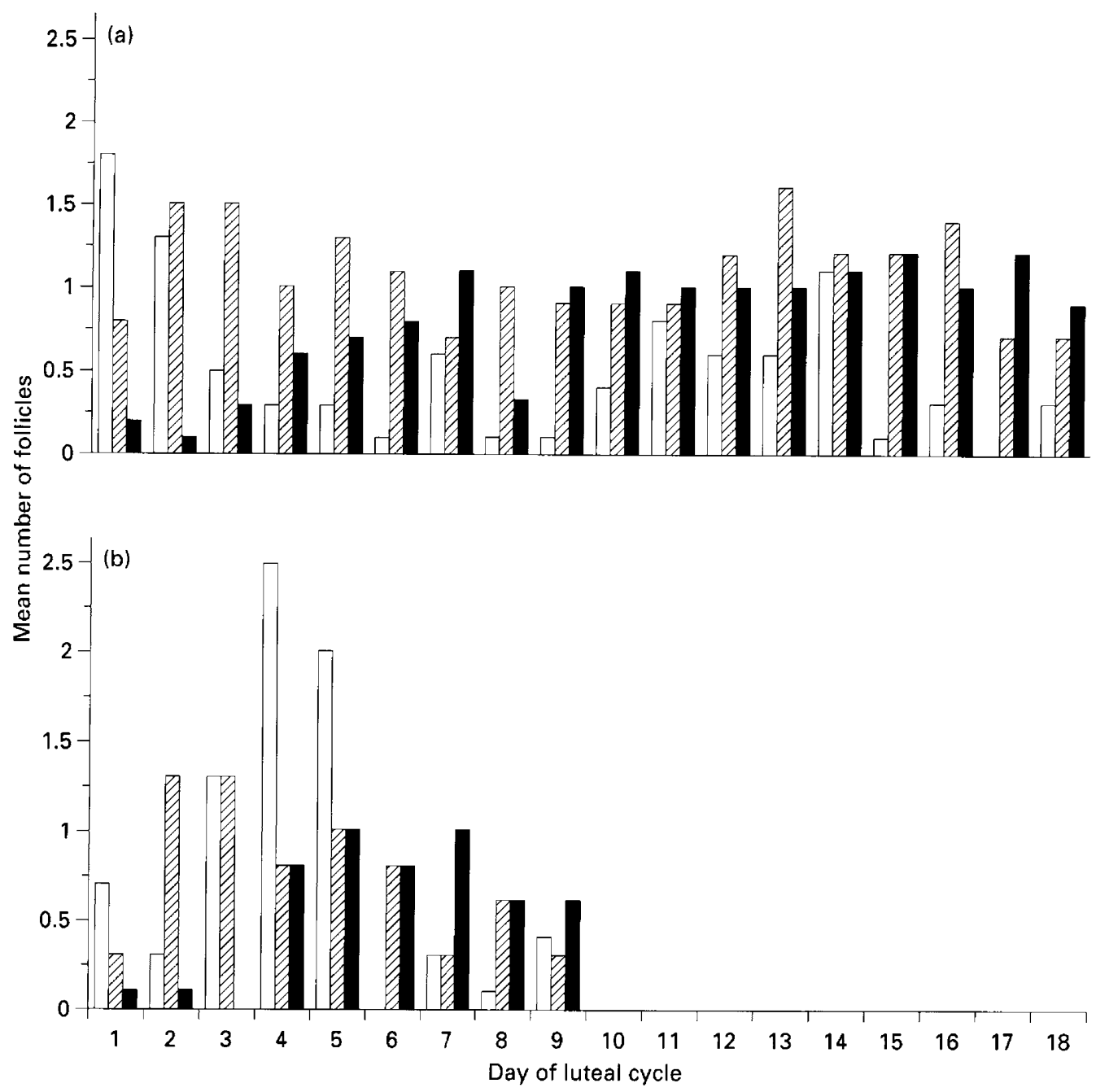

Fig. 3. Mean number of small ( $3 \mathrm{~mm} ; \square)$, medium $(4-5 \mathrm{~mm} ; \square)$ and large ( $\geq 6 \mathrm{~mm} ; \square$ ) follicles on each day of (a) normal luteal cycles $(n=9)$ and (b) short luteal cycles $(n=4)$ of red deer hinds.

diameter found on day 6-7. Individually tracked ovulatory and non-ovulatory follicles reached their maximum mean diameters ( $8.8 \mathrm{~mm}$ versus $3.8 \mathrm{~mm}$, respectively; $P<0.001$ ) on day 5.3 and day 3.9, respectively $(P>0.11)$, with a mean longevity of 7.8 days and 2.3 days, respectively $(P<0.001)$. The longevity of OvF was similar for both the short luteal cycles (7.8 days) and normal luteal cycles ( 7.9 days; $P>0.1$ ). The average last day of follicle presence for short luteal cycles was day 8.5 for $\mathrm{OvF}$ and day 4.9 for NOvF.

\section{Luteal structures}

Despite the unequivocal presence of plasma progesterone at concentrations typical of those during the luteal phase (Fig. 1), it was not possible to distinguish luteal structures by ultrasonography. It is assumed that, in red deer, luteal tissues are of similar echo density to surrounding ovarian stroma.

\section{Enlarged follicle phenomenon}

On six occasions involving four hinds during the breeding season, a single large follicle $(6-8 \mathrm{~mm})$ was observed to enlarge rapidly to diameters $>20 \mathrm{~mm}$. These exceptionally large structures persisted for 16-20 days, with a 10-15 day growth period and a 4-8 day regression period. While generally being fluid-filled spheres, echo images indicated considerable quantities of suspended particulate matter. In all cases, growth and regression of these structures was correlated with a 'luteal' pattern (after Jopson et al., 1990) of progesterone secretion (Fig. 5). This indicated that these exceptionally large follicles were at least in part luteinized structures, although the presence of other solid luteal structures could not be completely discounted.

\section{Follicular turnover during anoestrus}

Comparison was made among the follicular populations of hinds in April, September and November (late and early anoestrus, and mid-anoestrus, respectively). For all follicles present on any day, there were no significant differences between seasons in the overall mean number of follicles present $(P>0.10)$. However, a greater number of follicles of the small $(3 \mathrm{~mm})$ and large $(\geq 6 \mathrm{~mm})$ classes were recorded in November 

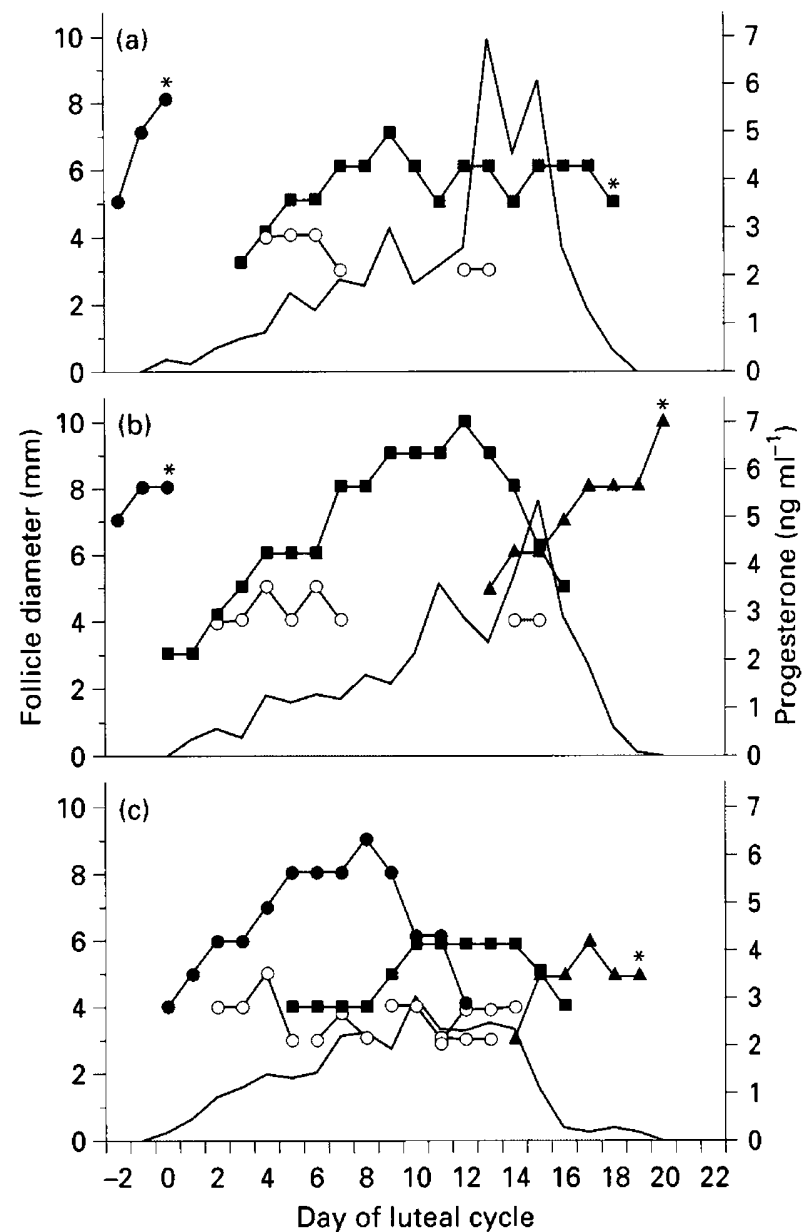

Fig. 4. Representative profiles of follicular growth patterns for 'dominant' follicles $(\bullet, \mathbf{\bullet}, \mathbf{\Delta})$ and subordinate follicles (0) during the normal luteal cycle, plotted relative to plasma progesterone concentrations (shaded area) for hinds exhibiting (a) one dominant follicle, (b) two consecutive dominant follicles and (c) three consecutive dominant follicles. *Indicates follicular rupture (ovulation).

$(P<0.001)$. Furthermore, the mean size of all follicles present on any day, in terms of diameter and calculated volume, was significantly less during mid-anoestrus $(P<0.001)$.

For follicles individually tracked from emergence $(3 \mathrm{~mm})$ to disappearance, no fewer than 2 days later (see Fig. 2d), initial size, average size, maximum size and longevity were significantly greater during the breeding season (June-September) than during mid-anoestrus (November) $(P<0.05)$. This was particularly pronounced for the largest follicle on any 1 day. The peak size and overall longevity of the non-ovulatory largest follicle during the breeding season $(7-8 \mathrm{~mm}$ and 8-16 days, respectively) were markedly greater than during mid-anoestrus (5-6 mm and 4-8 days, respectively; Fig. 2).

\section{Follicular growth during ovine FSH (superovulation) treatment}

The data are expressed only as the daily incidence of follicles of various size classes owing to an inability to track individual follicles reliably in the superovulated hinds. Treated and control hinds exhibited similar mean numbers of follicles

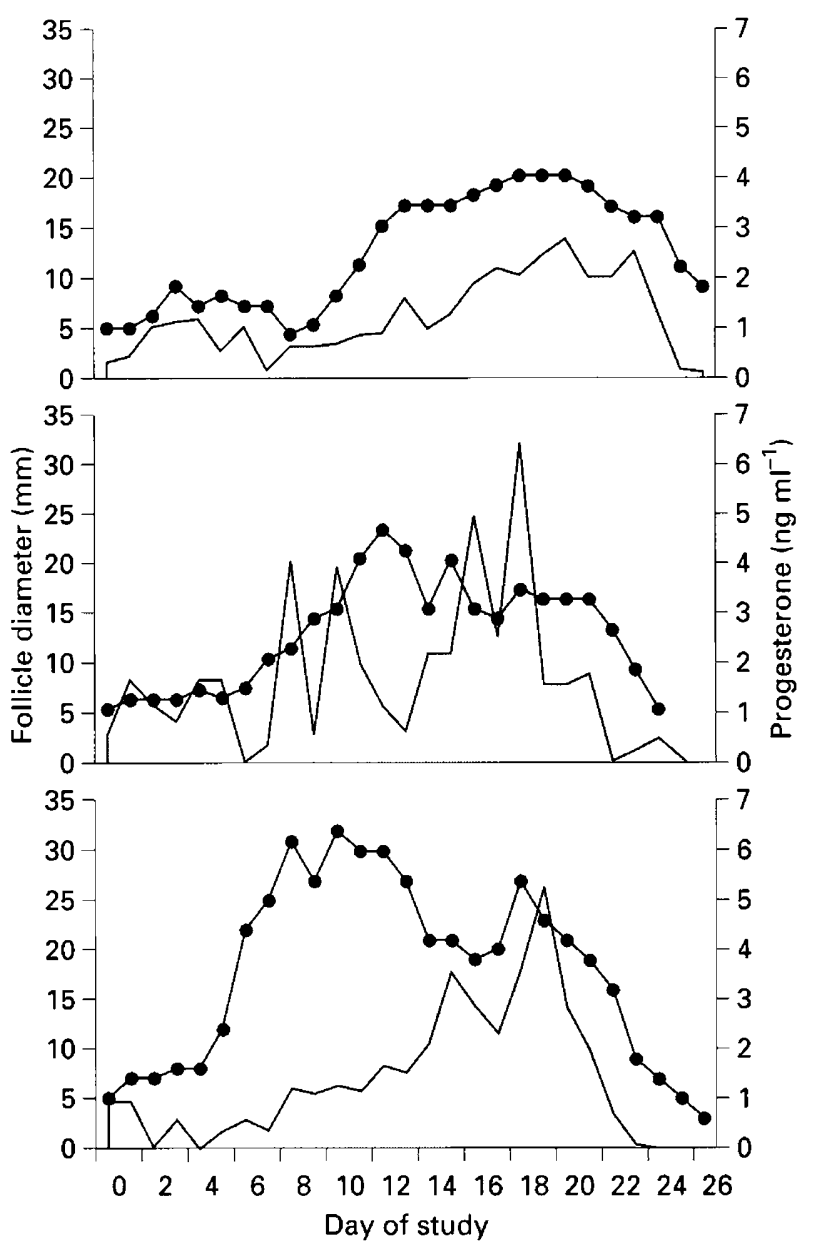

Fig. 5. Examples of the 'enlarged' follicle phenomenon. Profiles of follicle diameter (-) are plotted relative to those of plasma progesterone concentrations (shaded area).

$\geq 3 \mathrm{~mm}$ diameter at the start of the FSH injection regimen ( 1.8 versus $2.3 ; P>0.1), 8$ days into the CIDR device insertion period (Fig. 6). However, by the fourth injection, $48 \mathrm{~h}$ later, the ovaries of treated hinds contained significantly more follicles (6.7 versus $3.8 ; P<0.05$ ) than the controls. This was primarily the result of increased numbers of follicles $3 \mathrm{~mm}$ in diameter (Fig. 6). This trend continued up to the sixth FSH injection (9.2 versus 3.5 follicles). By the eighth and final FSH injection, the difference between the two groups of hinds was maximal ( 9.8 versus 3.0 follicles), and for the superovulated hinds there was a reduction in the number of new follicles but a corresponding increase in the number of medium-sized follicles. While the mean number of total follicles in control hinds fluctuated between 2.3 and 4.0 for the remainder of the monitoring period (Fig. 6a), the treated hinds exhibited a steady decline from a peak of 9.8, at $24 \mathrm{~h}$ after CIDR device removal, to a nadir at 4.0, 7 days later (Fig. 6b). During this period the larger follicle classes predominated (Fig. 6b). Although most of the large follicles ovulated during this period, nearly $40 \%$ persisted throughout the monitoring period, many of which became abnormally large (>15 mm diameter). The prostaglandin analogue, administered on day 10, had eliminated all of these structures by day 12 . 


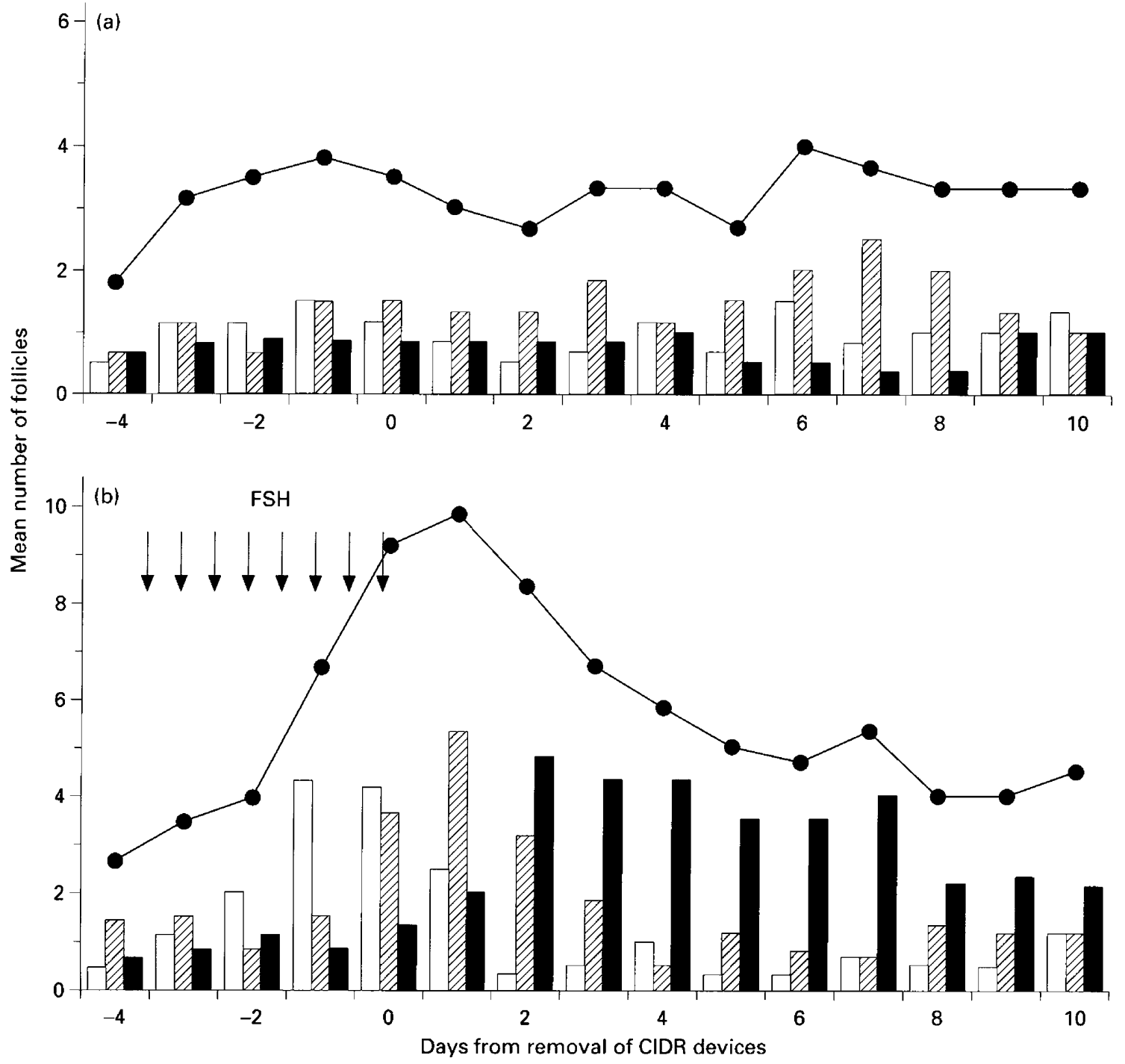

Fig. 6. Mean numbers of small ( $3 \mathrm{~mm} ; \square)$, medium (4-5 mm; $\square$ ) and large ( $\geq 6 \mathrm{~mm} ; \square$ ) follicles (histogram) and total follicles (line graph) around removal of intravaginal progesterone-releasing (CIDR) devices for (a) control hinds $(n=6)$ and (b) hinds receiving ovine FSH to induce superovulation $(n=6)$.

\section{Discussion}

Ovarian follicular dynamics of cervid species are not well understood. The present study is one of the first attempts to use ultrasonography to monitor ovarian follicular dynamics in deer. However, the possible limitations and artefacts imposed by the surgical modification of the red deer hinds in this study need to be considered. Previous attempts at transvaginal and transrectal ultrasonography in mature hinds yielded low success rates $(<50 \%)$ in locating individual ovaries. Furthermore, the small size of the animals and fragility of the rectal wall precluded the use of rectal manipulation of the reproductive tract. In this study, the intact ovaries were permanently relocated to the vaginal wall, which allowed repeated and consistent visualization via transvaginal scanning. However, it is possible that the high incidence of abnormally large follicles was an artefact due to relocation of the ovaries; ovulation failure perhaps arising from interfering scar tissues. The fact that these abnormal structures were of similar longevity to that of a normal corpus luteum (about 18 days), contained particulate matter and arose coincident with temporal increases in progesterone concentrations, indicates a degree of luteal function. Apart from this single artefact, there was unequivocal evidence of normal cyclical luteal function and changing follicular activity similar to that seen in normal red deer hinds (Jopson et al., 1990), suggesting that the ovaries in all 12 selected hinds were functional.

On average, between three and four follicles $>3 \mathrm{~mm}$ in diameter were present on the ovaries at any point in time, with one of these follicles generally being in the largest class $(\geq 6 \mathrm{~mm})$. These observations on red deer are similar to those obtained recently from normal (not surgically modified) fallow deer (Dama dama) during the oestrous cycle and late anoestrus (G. W. Asher, I. C. Scotł and E. K. Inskeep, unpublished). In a recent study of ovaries recovered at slaughter from red deer hinds during the periovulatory stage of the oestrous cycle, 
variable but generally larger numbers (4-81) of follicles $\geq 2 \mathrm{~mm}$ in diameter were identified at dissection, and the overall mean numbers were similar to those recorded for sheep and cattle (McLeod et al., 1996). However, these data indicate that most of these follicles were within the $2-3 \mathrm{~mm}$ diameter class, and beyond the reliable resolution limit of the ultrasonographic equipment used in the present study. Therefore, high levels of atresia may occur among follicles of $2-3 \mathrm{~mm}$ diameter, resulting in a significantly reduced pool of follicles $\geq 3 \mathrm{~mm}$ in diameter. If this is the case, the data presented here are clearly limited with respect to a general definition of follicular dynamics of small follicles because of the limits imposed by ultrasonography. Nevertheless, despite this limitation, we were able to determine that there were non-random patterns of appearance, growth and regression of follicles $\geq 3 \mathrm{~mm}$ in diameter, as has been shown in other species (for example, cattle: Sirois and Fortune, 1988; sheep: Lucy et al., 1992; Noel et al., 1993; and camelids: Bravo et al., 1990, 1991).

There was evidence of emergence of new ( $\geq 3 \mathrm{~mm}$ ) follicles being especially pronounced on day 1 and day 14 of the oestrous cycle. Conversely, the growth of follicles beyond $6 \mathrm{~mm}$ in diameter occurred to a greater degree during the latter half of the cycle. On the basis of cattle studies (Sirois and Fortune, 1988; Ginther et al., 1989), a more pronounced delineation of these events due to synchronous waves of dominant follicles had been expected. In fact, individual profiles of continuously tracked follicles during the red deer luteal cycle indicated highly variable and generally non-synchronous patterns of growth and regression of the largest follicle. While most oestrous cycles were associated with the emergence of either two or three consecutive large follicles, there was one case in which a single large follicle persisted for almost the entire duration of the cycle. In general, the emergence of one or two new $(\geq 3 \mathrm{~mm})$ follicles occurred only during the early growth phase of the presumptive preovulatory follicle early in the oestrous cycle or after the demise of the preceding large follicle. This finding indicates a probable endocrine 'dominance' by the (invariably single) large follicle. Moreover, the asynchrony of a turnover of large follicles between observed cycles would tend to obscure any trends in emergence of new follicles $\geq 3 \mathrm{~mm}$ in diameter. Unfortunately, there are insufficient data to analyse on the basis of number of follicle waves, as is frequently the case for studies on cattle exhibiting either two or three waves (Fortune and Sirois, 1989; Ginther et al., 1989).

The variable longevity of the ovulatory follicle in red deer raises interesting questions in relation to fertility. The ovulatory follicle in cattle is generally selected $<6$ days earlier to ensure a healthy oocyte at ovulation. Artificial prolongation of the longevity of the presumptive ovulatory follicle is associated with a marked reduction in conception rate due to oocyte senescence and abnormal embryonic development (Wishart, 1977; Mihm et al., 1994). The ability of red deer to exhibit high conception rates (Fennessy et al., 1991) while exhibiting highly variable, and sometimes apparently excessive, longevity of the ovulatory follicle indicates the possibility of a different process of follicular and oocyte development than that which occurs in cattle. However, on the basis of the limited data set in the present study, it is perhaps not safe to assume that aged follicles (> IO days) are a common feature in red deer. Certainly, two- or three-wave patterns of primary follicle development were more common, and were comparable with those seen in other domestic ruminants.

The follicular response of the red deer hinds to exogenous ovine FSH is consistent with studies on the induction of superovulation in other species (Robertson et al., 1993). Evidence of new follicles developing to $\geq 3 \mathrm{~mm}$ in diameter occurred mainly within the first $48 \mathrm{~h}$ of treatment. Thereafter, fewer new antral follicles $\geq 3 \mathrm{~mm}$ in diameter were observed but the incidence of the larger classes increased, indicating the growth of a greater than normal number of large follicles. However, disappearance of large follicles after removal of the CIDR device was not instantaneous, suggesting asynchrony with respect to ovulation. Furthermore, approximately $40 \%$ of large follicles failed to ovulate altogether, and ultimately enlarged into abnormal structures. These phenomena are common features of superovulation programmes in red deer (Asher et al., 1992; Fennessy et al., 1994). It is notable that most hinds exhibited a large $(\geq 6 \mathrm{~mm})$ follicle at the start of the ovine FSH injections. To what extent this large follicle influenced the superovulatory process was not assessed but, on the basis of recent research on superovulation in cattle, it is possible that it exerts a profound effect on the growth and development of smaller follicles. Future studies on improving superovulation responses in red deer hinds may benefit from the removal of the existing 'dominant' follicle.

The present study has highlighted a change in the dynamics of ovarian follicular turnover within the non-breeding season. Scanning in mid-anoestrus (November) in this species revealed reduced growth and a more rapid turnover of the largest follicles compared with that observed in late anoestrus (April) and early anoestrus (September). For most hinds in the study, these three periods were all associated with little or no cyclic luteal activity, as evidenced by low concentrations of progesterone. Therefore, as advanced by Curlewis et al. (1991) for Pére David's deer (Elaphus davidianus), anoestrus is in itself a dynamic state despite uniformity in anovulation. The neural signals associated with ovarian function during this period have not been fully resolved, but several studies on seasonally breeding cervids have demonstrated marked changes in LH pulse frequency and amplitude throughout anoestrus (Curlewis et al., 1991; Meikle and Fisher, 1996).

In conclusion, this study has demonstrated that there are discrete patterns of antral follicle growth and regression during both the breeding and non-breeding seasons of red deer hinds. The oestrous cycle was characterized by a variable number (1-3) of follicular waves from which a single large $(\geq 6 \mathrm{~mm})$ follicle emerged. It is speculated that this large follicle regulated the timing of emergence of the next wave of follicles $\geq 3 \mathrm{~mm}$. The variable, and sometimes excessive, longevity observed for the presumptive ovulatory follicle was a characteristic feature in these studies. Whether this is an artefact of the experimental procedure or a typical feature in untreated animals is unknown. Finally, these studies established that anoestrus in red deer hinds represents a period of dynamic changes in follicular growth and regression.

The authors are indebted to the farm staff at Invermay for animal management. Progesterone analyses were performed by R. Porteous and T. Manley. B. McLeod and K. McNatty kindly reviewed earlier manuscripts. 


\section{References}

Adam CL, Moir CE and Atkinson T (1985) Plasma concentrations of progesterone in female red deer (Cervus elaphus) during the breeding season, pregnancy and anoestrus Journal of Reproduction and Fertility 74 631-636

Asher GW (1990) Effect of subcutaneous melatonin implants on the seasonal attainment of puberty in female red deer (Cervus elaphus) Animal Reproduction Science 22 145-159

Asher GW, Fisher MW, Jabbour HN, Smith JF, Mulley RC, Morrow CJ, Veldhuizen FA and Langridge M (1992) Relationship between the onset of oestrus, the preovulatory surge of luteinizing hormone and ovulation following oestrous synchronization and superovulation of farmed red deer (Cervus elaphus) Joumal of Reproduction and Fertility 96 261-273

Asher GW, Fisher MW, Fennessy PF, Mackintosh CG, Jabbour HN and Morrow CJ (1993) Oestrous synchronization, semen collection and artificial insemination of farmed red deer (Cervus elaphus) and fallow deer (Dama dama) Animal Reproduction Science 33 241-265

Bravo PW, Fowler ME, Stabenfeldt GH and Lasley BL (1990) Ovarian follicular dynamics in the llama Biology of Reproduction 43 579-585

Bravo PW, Stabenfeldt GH, Lasley BL and Fowler ME (1991) The effect of ovarian follicle size on pituitary and ovarian responses to copulation in domesticated South American camelids Biology of Reproduction 45 553-559

Clutton-Brock TH, Guinness FE and Albon SD (1982) Red Deer: Behaviour and Ecology of Two Sexes University of Chicago Press, Chicago

Curlewis JD, McLeod BJ and Loudon ASI (1991) LH secretion and response to GnRH during seasonal anoestrus of the Père David's deer hind (Elaphurus davidianus) Journal of Reproduction and Fertility 91 131-138

Duckworth JA and Barrell GK (1992) The breeding season of pubertal red deer hinds Proceedings of the New Zealand Society of Animal Production 52 183-186

Fennessy PF, Mackintosh CG, Shackell GH and Whaanga AJ (1991) Artificial insemination and synchronised natural breeding in red deer Proceedings of the New Zealand Society of Animal Production 51 327-331

Fennessy PF, Asher GW, Beatson NS, Dixon TE, Hunter JW and Bringans MJ (1994) Embryo transfer in deer Theriogenology 41 133-138

Fisher MW, Asher GW, Meikle LM and Newman RE (1994) Cloprostenolinduced luteolysis in the red deer hind: the effects of age, dose, number of corpora lutea and the later stages of the oestrus cycle Animal Reproduction Science 35 99-109

Fortune JE (1993) Follicular dynamics during the bovine estrous cycle: a limiting factor in improvement of fertility? Animal Reproduction Science 33 111-125

Fortune JE and Sirois J (1989) The use of ultrasonography to study the regulation of foilicular development in cattle and horses. In Follicular Development and the Ovulatory Response 23 11-20 Eds A Tsafriri and N Dekel. Serono Symposium Review, San Francisco

Ginther OJ and Kot K (1994) Follicular dynamics during the ovulatory season in goats Theriogenology 42 987-1001

Ginther OJ, Knopf L and Kastelic JP (1989) Temporal associations among ovarian events in cattle during oestrous cycles with two and three follicular waves Journal of Reproduction and Fertility 87 223-230
Guinness FE, Lincoln GA and Short RV (1971) The reproductive cycle of the female red deer, Cervus elaphus L. Journal of Reproduction and Fertility $\mathbf{2 7}$ $427-438$

Johnson SK, Dailey RA, Inskeep EK and Lewis PE (1996) Effect of peripheral concentrations of progesterone on follicular growth and fertility in ewes Domestic Animal Endocrinology 13 69-79

Jopson NB, Fisher MW and Suttie JM (1990) Plasma progesterone concentrations in cycling and in ovariectomised red deer hinds: the effect of progesterone supplementation and adrenal stimulation Animal Reproduction Science 23 61-73

Lincoln GA and Short RV (1980) Seasonal breeding: nature's contraceptive Recent Progress in Hormone Research 36 1-52

Lucy MC, Savio JD, Badinga L, De La Sota R and Thatcher WW (1992) Factors that affect ovarian follicular dynamics in cattle Journal of Animal Science $\mathbf{7 0}$ 3615-3626

McLeod BJ, Meikle LM, Heath DA, McNatty KP, Fisher MW and Whaanga AJ (1996) Ovarian follicle development in the red deer hind Proceedings of the New Zealand Society of Animal Production 56 370-372

Meikle LM and Fisher MW (1996) Regulation of reproductive seasonality in the red deer hind: oestradiol-dependent and -independent influences on the patterns of LH concentrations Journal of Reproduction and Fertility 106 $213-220$

Mihm M, Baguisi A, Boland MP and Roche JF (1994) Association between the duration of dominance of the ovulatory follicle and pregnancy rate in beef heifers Journal of Reproduction and Fertility 102 123-130

Noel B, Bister JL and Paquay R (1993) Ovarian follicular dynamics in Suffolk ewes at different periods of the year Journal of Reproduction and Fertility 99 $695-700$

Ravindra JP, Rawlings NC, Evans ACO and Adams GR (1994) Ultrasonographic study of ovarian follicular dynamics in ewes during the oestrous cycle Journal of Reproduction and Fertility 101 501-509

Robertson L, Cattoni JC, Shand RI and Jeffcoate IA (1993) A critical evaluation of ultrasonic monitoring of superovulation in cattle British Veterinary Journal 149 477-484

SAS (1992) SAS Users Guide Version 6 Statistical Analysis System Institute Inc., NC

Schrick FN, Surface RA, Pritchard JY, Dailey RA, Townsend EC and Inskeep EK (1993) Ovarian structures during the estrous cycle and early pregnancy in ewes Biology of Reproduction 49 1133-1140

Sirois J and Fortune JE (1988) Ovarian follicular dynamics during the estrous cycle in heifers monitored by real-time ultrasonography Biology of Reproduction 39 308-317

Steel RGD and Torrie JH (1980) Principles and Procedures of Statistics (2nd Edn) McGraw Hill Inc., New York

Wishart DF (1977) Synchronisation of oestrus in heifers using steroid (SC 5914, SC 9880 and SC 21009) treatment for 21 days. 1. The effect of treatment on pregnancy rate to artificial insemination Theriogenology 8 $233-247$ 